\title{
Revision of the Oriental genus Idiotrephes (Heteroptera: Nepomorpha: Helotrephidae)
}

\author{
Miroslav PAPÁČEK ${ }^{1 *}$ and Herbert ZETTEL ${ }^{2}$ \\ ${ }^{1}$ Pedagogical Faculty, University of South Bohemia, and Institute of Entomology, Czech Academy of Sciences, České Budějovice, \\ Czech Republic \\ ${ }^{2}$ Naturhistorisches Museum in Wien, 2. Zoologische Abteilung, Burgring 7, A-1014 Wien, Austria
}

Key words. Helotrephidae, Idiotrephes, revision, taxonomy, key, morphology, biology, new species, Thailand Vietnam, Malaysia, Indonesia, Oriental

\begin{abstract}
The Oriental helotrephid genus Idiotrephes Lundblad, 1933, is taxonomically revised. Species discrimination is based on male genitalia and female terminalia. Three species groups are recognized. The I. chinai group contains I. chinai Lundblad, 1933 (type species; from Sumatra, Borneo, and West Malaysia) and three newly described species; I. asiaticus sp. n. (from Vietnam, Thailand, and west Malaysia); I. yupae sp. n., and I. polhemusi sp. n. (both from Thailand). The I. maior group contains I. maior Papáček, 1994; I. meszarosi Papáček, 1995 (both from Vietnam), and I. hainanensis sp. n. (from Hainan, China). The I. thai group consists of two newly described species from north and northeast Thailand, $I$. thai sp. $\mathrm{n}$. and $I$. shepardi $\mathrm{sp}$. n. In addition, some features of biology and morphology of the ovipositor are also included.
\end{abstract}

\section{INTRODUCTION}

Although Idiotrephes species are relatively common and abundant in southeast Asia, the genus Idiotrephes was described by Lundblad (1933) based on material of only a single new species, I. chinai Lundblad, 1933, from Sumatra. More than sixty years later, Papáček (1994, 1995) described two further species, $I$. maior and $I$. meszarosi, from Vietnam. Records of $I$. chinai from Vietnam (Papáček, 1994) and Thailand (Zettel, 1995) refer to a sibling species, described here as new, $I$. asiaticus. Zettel (1997b) figured the types of I. chinai and recorded this species from Sarawak, Borneo; Kovac \& Yang (1990) also recorded this species from peninsular Malaysia. To clarify the situation between these two sibling species, and to describe further new species from the collection of the Natural History Museum Vienna and some private collections, a complete taxonomic revision of the genus became necessary.

Idiotrephes is presently included within the tribus Limnotrephini Polhemus, 1990, of the subfamily Helotrephinae (Polhemus, 1990). Recently, Zettel (1997a) discussed the doubtful monophyly of this tribe in the present phylogenetic system. The genus Idiotrephes is very well defined by some important autapomorphies, as indicated in the generic diagnosis below. It is easily dist- iguished from other genera of its distribution area with the key of Zettel (1998).

\section{MATERIAL AND METHODS}

Dry card-mounted specimens as well as material preserved in $70 \%$ ethanol were studied. Male and female terminalia were both dry-prepared and mounted on slides for examination of morphology and for measurements**.

Measurements and scales in figures of all the structural parts are in millimeters $(\mathrm{mm})$. Morphometrical characters measured in male and female genitalia are defined in Figs 1-3 and their legends. Numbers of specimens, males and females, and their structures measured in individual species are variable depending on their availability (see paragraphs "Material examined"). For this reason separate data for different morphs and sexes as well as statistical data are not presented in tables but only as ranges of measurements. Figures of terminalia represent ventral view.

Terminology used here is derived mainly from Papáček et al. $(1988,1989)$. Abbreviations in the text are as follows: brach. specimen with brachypterous forewing; macr. - specimen with macropterous forewing; other abbreviations are presented in the next section, and in Figs 1-4 and 62. Data about material examined are presented here as given on the labels in the specimens' depositories.

\section{Depositories}

CASS - Chinese Academy of Sciences, Institute of Applied Ecology, Shenyang, China; CMUT - Chiang Mai University, Faculty of Sciences, Department of Biology, Chiang Mai, Thailand; CNTN - Coll. N. Nieser, Tiel, The Netherlands; CPCB -

\footnotetext{
* Mail address: Pedagogical Faculty, University of South Bohemia, Jeronýmova 10, 37115 České Budějovice, Czech Republic; e-mail: papacek@pf.jcu.cz.

** Note: It is relatively easy to sex Idiotrephes spp. specimens. Males have a slightly asymmetrical, completely brownish abdominal sternum 7 (and sternum 8), with a moderately curved hind margin but without any incision or impression. Females have an asymmetrical abdominal sternum 7 with a dextrocaudal incision (see, e.g., Figs 30-33) or emarginations (see, e.g., Figs 49-53), and with a light, mostly yellowish, dextrocaudal impression. The architecture of the terminalia of both sexes was figured and explained, e.g., by Lundblad (1933, Figs 44 C, G, H, I, K, L, M), Papáček (1994, Figs 9-16, 17-21; 1995, Figs 3, 4, 16-19), and Zettel (1997b, Figs 23, 24, 31).
} 
Coll. P.P. Chen, Beijing, China; CSS - Coll. W.D. Shepard, California State University, Sacramento, USA; CZVA - Coll. H. Zettel, Vienna, Austria; JTPC - Coll. J.T. Polhemus, Englewood, Colorado, USA; FSFM - Coll. D. Kovac, Forschungsinstitut Senckenberg, Entomologie I, Frankfurt am Main, Germany; KKUA - Khon Kaen University, Faculty of Agriculture, Department of Entomology, Khon Kaen, Thailand; NHMW - Naturhistorisches Museum in Wien, Vienna, Austria; NHRS - Naturhistoriska Riksmuseet, Stockholm, Sweden; UBCB - Coll. M. Papáček, University of South Bohemia, České Budějovice, Czech Republic.

\section{Genus Idiotrephes Lundblad, 1933}

Idiotrephes Lundblad, 1933: 120.

Type species: Idiotrephes chinai Lundblad, 1933 (by monotypy).

Diagnosis. Small (1.30-1.78 mm) Limnotrephini (sensu Polhemus, 1990) with semiglobular appearance; colour yellowish, dorsally with scattered, usually small, dark spots of varying size and number, usually more distinct in macropterous specimens; on head more confluent than on pronotum, mesoscutellum, and hemelytra; lateral carina of cephalonotum not continuous across eye, but indenting it conspicuously in the posterior part (Fig. 4), without distinct differences between morphs; in dorsal view of total insect cephalonotum distinctly shorter than posterior part of body; cephalonotum and mesoscutellum shining, without or with very sparse and fine or shallow spots, that on head not correlated with colour pattern, on thorax and hemelytra much smaller than dark spot with same distribution; hemelytra with coarser punctation and sparse, but quite long hairs; antenna two-segmented in both morphs; rostrum short, stout, reaching approximately posterior corner of prosternal carina; tarsal formula (number of tarsal segments on fore-, middle -, and hind leg) 1-1-2; propleural plate at inner corner rounded (Fig. 4); prosternal, mesosternal, metasternal carinae simple; abdominal carinae on sternum 2 and 3 high, on sternum 4 very low or lacking*; sterna 4-6 medially fused, with sutures more or less reduced.

Male genitalia. Pygophore with sinistral process; aedeagus with club-shaped tip, and distal part elongate and narrow in most species (Figs 5, 8, 11, 14, 17, 18, 21, $24,27,34,37,40$ ) except in $I$. thai group (Figs 43, 46); left paramere of very characteristic shape, with more or less rectangular base and an S-shaped, slender distal part (Figs 6, 9, 12, 15, 19, 22, 25, 28, 35, 38, 41, 44, 47); right paramere slightly shorter than left, elongate, distally obliquely truncate $[$ I. chinai group (Figs $7,10,13,16,20$, 23, 26, 29)]; tapered [I. maior group (Figs 36, 39, 42)] or obtuse [I. thai group (Figs 45, 48)].

Female terminalia. Sternum 7 asymmetrical, with large or small incision on its posterodextral margin (except in the $I$. thai group, with shallow emargination and ventral impression), and often with more or less distinct, hookshaped ridge (dextrocaudal break) on ventral surface

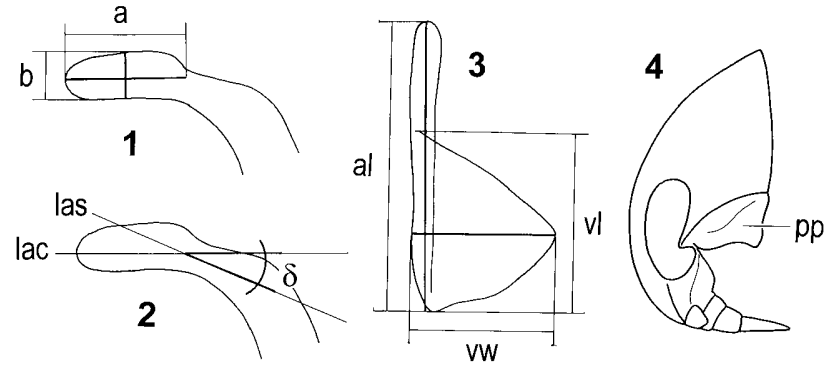

Figs 1-4. 1-3-morphometrical characters of Idiotrephes species. 1, 2 - male, tip of aedeagus; 3 - female, left valvula. a length of apical club-shaped process; $b$ - width of apical clubshaped process (measured at middle of the "a"); $\delta$ - angle $\delta$, i.e., angle between longitudinal axis of the club-shaped process (lac) and longitudinal axis of the subapical narrowed part of aedeagus (las); al - length of apodeme of the first valvula; vl - length of the first valvula; vw - width of valvula. 4 - diagrammatic lateral view of cephalonotum of Idiotrephes spp.; pp - propleural plate.

(Figs 30-33, 49-53); ovipositor with first valvulae conspicuously shorter than their apodemes (Figs 54-62).

Larvae not strongly flattened.

The asymmetrical female abdominal sternum 7 with a dextrocaudal incision or impression and a dextrocaudal break, the club-shaped apex of aedeagus, and a very characteristic shape of male left paramere, are autapomorphies of Idiotrephes.

Wing polymorphism. Papáček (1995) found three different types of pterygopolymorphism in Idiotrephes species: (a) fore and hind wing macropterous [in I. "chinai" (= asiaticus sp. n.)]; (b) forewing brachypterous and hind wing micropterous; (c) forewing and hind wing brachypterous (in I. maior). The macropterous morph (a) is easily recognized by the presence of a claval suture and a separated embolium on the hemelytron. The other morphs $(b, c)$ are distinguishable only by hindwings, and combination (b) is most common in Helotrephidae, whereas the frequency of macropterous morphs (a) differs between species, obviously depending on their habitat preferences (see, e.g., Zettel, 1999). Brachypterous hind wings (c) have so far been rarely observed in Helotrephidae (see Papáček et al., 1989).

Most Idiotrephes species were collected in often small stagnant waters (see below). The consequent necessity to migrate, if the water body dries up, is expressed by a relatively high rate of macropterous morphs compared with rates in most other helotrephid genera.

Species discrimination. The relatively minute Idiotrephes species are very uniform in their external appearance. They are not readily distinguishable from each other by characters of cephalonotum, pterothorax, basal abdominal part, or by size. The colour pattern varies slightly within some species, but does not serve to distinguish species. Size varies considerably within species, as females and macropterous morphs are larger than males and hind-wing-brachypterous morphs. For example, the

\footnotetext{
* Polhemus (1990) and Zettel (1998) state that the sternal carinae reach sternum 5, because the very low carina of sternum 4 appears sometimes (especially in males) longer than sternum 4 . The suture between sterna 4 and 5 is not present medially, and there is no interruption of the carina, which would indicate its presence on sternum 5 .
} 


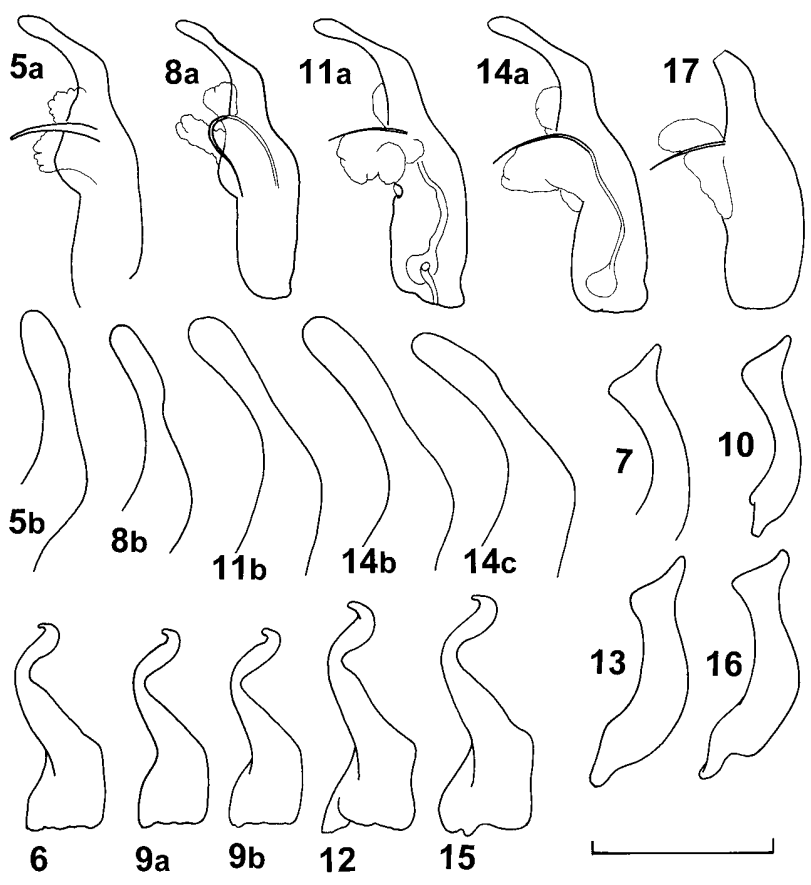

Figs 5-17: Idiotrephes chinai, variability of male genitalia. 5-7 - lectotype; 8-10 - specimen from Sarawak; 11-13 specimens from Singapore; 14-17 - specimens from west Malaysia (Selangor, Ulu Gombag). 5, 8, 11, 14, 17 - aedeagus, $\mathrm{b}$, c, respectively - shapes of tips of aedeagi (the same lettering used in the following figures); $14 \mathrm{c}$ - somewhat aberant shape; 17 - aedeagus with broken tip (after mating?); 6, 9, 12, 15 - left paramere; $7,10,13,16$ - right paramere (different alternative aberrant shapes). Scale bar: $0.2 \mathrm{~mm}(0.1 \mathrm{~mm}$ for Figs $5 \mathrm{~b}, 8 \mathrm{~b}$, $11 b, 14 b, c)$.

body lengths of different specimens of the same species can differ by 6-20\% (see Tables 1-3). However, if the same morphs and sexes of the same sympatric population are compared, species differ constantly. The intensity of punctation of the dorsal surface serves also as a weak character for species discrimination, but here also the differences between morphs are often stronger than between species. Also, the ventral carinae are relatively uniform in all species, but some may be recognized by special characteristics (e.g., I. thai sp. n. by the more ventrad-pointing apex of the metasternal carina). Reliable species identification is based on the examination of male genitalia, which also bear the main characters for distinguishing the three species groups. At the apex of the aedeagus, only two species show some intraspecific variability between specimens or local populations, I. chinai and I. asiaticus. The apices of the right paramere and several characters of the left paramere are very constant within species, and can be used to distinguish some species with certainty. The female abdominal sternum 7 (= subgenital plate) and first valvulae of ovipositor serve best to distinguish females. Only a few species (e.g., I. chinai and I. asiaticus; the species of the I. maior group) have such similar abdominal sterna 7 that identification of females should be confirmed by the first valvulae of females, and by examination of males from the same sampling. The relative morphometrical parameters of the tip of the aedeagus and the first valvulae (see Figs 1-3) can be used as additional differential characters.

Biology and habitats. The life cycle, nutrition, and most other aspects of the biology of Idiotrephes are known only in I. asiaticus* (cf. Papáček, 1993), and this knowledge is limited. I. asiaticus is with high probability a bivoltine species. The females lay eggs in small groups (2-4 eggs/group) on the surface of different objects in the water (rocky bottom, stones, gravel, plants, artificial objects). The ovipositional period lasts more than one month and starts immediately after mating. Preimaginal development lasts about two months; individual stadia are 10-17 days. Idiotrephes asiaticus is a predaceous water bug that attacks a large spectrum of prey (e. g., small dipteran, ephemeran or heteropteran larvae, cladocerans, copepods, annelids, rotifers, and protozoans). The last two instars as well as adults feed also on earlier instars. No prey preference was found. Rather, size seems to be the most important feature in the choice of prey and the attack.

Idiotrephes species were found in a variety of habitats. Unlike Distotrephes species, they are never found in lotic areas of streams, but in lentic places or stagnant waters. Lentic bays of streams and rivers, as well as small pools on the banks of streams, are preferred habitats. Artificial stagnant waters are also inhabited by some species, although in southeast Asia these habitats are usually dominated by Tiphotrephes indicus (Distant, 1910). Idiotrephes species can live under extreme and changing environmental conditions (temperature, velocity of flow, turbidity, dry and wet seasons, prey availability), especially in ephemeral water bodies as lithotelms on the rocky bottom of rivers or streams in the monsoonal area. Thus they are not only eurytopic but also very plastic and stress-tolerant. More information on habitats are given after the description of each species.

Distribution. Southeast Asian mainland, Hainan, Sumatra, Borneo; limited to the east by Wallace's Line (sensu Dickerson et al., 1928), and unknown from Java and Palawan so far. The highest diversification of the genus is in Indochina and in northern parts of Thailand. The distribution of individual species of the genus Idiotrephes is presented in Fig. 71.

\section{The Idiotrephes chinai group}

The Idiotrephes chinai group is a complex of several closely related, partly allopatric, partly sympatric species, and intraspecifically varying local populations. The authors are aware that the present study on this group based on classical morphology only - is a preliminary one. The group as a whole is well defined. Common characters of the species are: (1) distal part of the aedeagus

\footnotetext{
* Papáček (1993) presented some data based on laboratory rearing of $I$. "chinai" (= asiaticus sp. n.) under artificial "central European conditions". Material for this rearing (macropterous population - see also Papáček, 1994) was collected in lithotelms of the rocky bed of the Dong Nai River (Dong Nai Prov., Nam Cat Tien National Park, Vietnam) and transported to České Budějovice in 1989. Some results of laboratory observations were confirmed later (1995) in the field at this locality.
} 


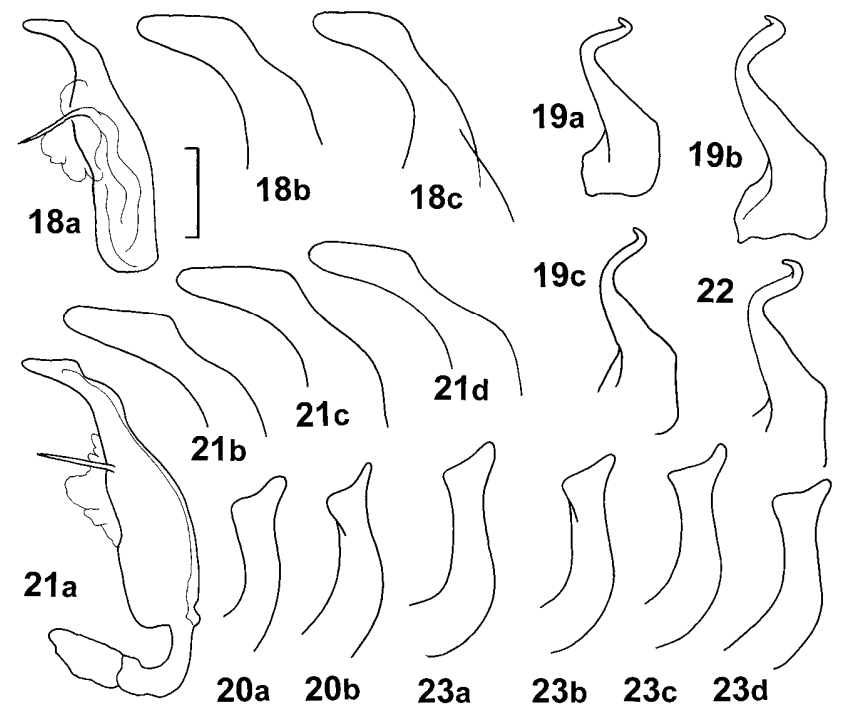

Figs 18-23: Idiotrephes asiaticus, variability male genitalia. 18,21 - aedeagus; 19,22 - left paramere; 20,23 - right paramere. 18a, b, c, 19a, b, c, 20a, b - from Vietnam (Nam Cat Tien N. P.); 21-23 - from Thailand (21a, b, 23a, b - from Khon Kaen; 21d, 23c - from Satun; 21c, 22, 23d - from Phitsanulok). Scale bar: $0.1 \mathrm{~mm}(0.05 \mathrm{~mm}$ for Figs $18 b, \mathrm{c}, 21 \mathrm{~b}, \mathrm{c}, \mathrm{d})$.

(distal of opening) long and slender; (2) apex of the right paramere obliquely truncate; (3) incision of the female sternum 7 deep; (4) break on the female abdominal sternum 7 either reduced (I. chinai, I. asiaticus) or weakly developed (I. yupae, I. polhemusi). Differences between species are mainly found in the shape of the incision of the female sternum 7 , in the tip of the aedeagus, and in certain characters of both parameres. Idiotrephes chinai is distributed in Sumatra, Borneo, Singapore, and the southern part of peninsular Malaysia; there are small differences among specimens of these island and mainland populations, but we lack enough material to decide if these differences are constant. Idiotrephes asiaticus is widely distributed in west Malaysia, Thailand, and Vietnam; small differences are found nearly among all populations studied; the tendency of prolongation of the aedeagus tip from north Vietnam westwards and southwards was observed. Idiotrephes asiaticus shows a higher variation of male genitalia than any other helotrephid species. Within the supposed distribution area of I. asiaticus, two further species can be distinguished by much more obvious differences; both are known only from single localities in Thailand. In Idiotrephes chinai and I. asiaticus the tip of the mesosternal carina is directed anteriad (Fig. 63), and the first left valvifer has a conspicuous laterocaudal lobe.
Idiotrephes chinai Lundblad, 1933

Idiotrephes chinai Lundblad, 1933: 120.

Idiotrephes chinai: Zettel 1997b: 124.

Diagnostic notes. Small species, tip of mesosternal carina oriented anteriad, metasternal carina pointed mostly ventrad, usually with oblique posterior corner (Fig. 63).

Male: Club-shaped tip of aedeagus with regular symmetrical or slightly asymmetrical (subparallel) outline (Fig. 8). Length and width of tip somewhat variable among and within some populations; angle $\delta$ less than $20^{\circ}$ (see also Tables 1, 3, and Figs 5, 11). Some specimens with broken tip of the aedeagus were also found (Fig. 17). Left paramere: Figs 6, 9, 12, 15. Apex of right paramere also somewhat variable (compare Figs 7, 10, 13, 16).

Female: Incision of the abdominal sternum 7 simple (Fig. 30a, b), in some populations or specimens with light U-shaped impression anteriorly from incision (Fig. 30c). Right anterolateral margin of abdominal sternum 7 with conspicuous lobe (Figs 30a, b, c). First valvulae small, uniform in all populations and female specimens, with rounded margins of its caudal corners. Posterocaudal lobe of the first left valvifer with conspicuous lobe (Fig. 54).

Comparative notes. See $I$. asiaticus $\mathrm{sp}$. n.

Type matrial. Lectotype (designated by Zettel, 1997b, brach. $\widehat{0}$, dissected and slide mounted): "Typus", "2274" [slide number], "Idiotrephes chinai Lundbl., §, Sumatra, bäck vid Balige. 1.4.1929." (NHRS); paralectotypes: 19 (dissected and slide mounted) "Allotypus", "2275", "Idiotrephes chinai Lundbl. \& Sumatra, göl vid Danan di Atas. 17.3.1929." (NHRS); 1 (only abdomen, mounted on slide) " 2276 ", "Idiotrephes chinai Lundbl. \& Sumatra, bäck vid Balige. 1.4.1929" (NHRS); 1 larva (mounted on slide) "2277", "Idiotrephes chinai Lundbl. Nymf. Sumatra, tillflödet till Danau di Atas. 17.3.1929" (NHRS); 1 $q$, (glued on paper card) "o", "Sumatra Thienemann", "F5 3 cc., 1/4", "Typus", "Limnotrephes [sic!] chinai Lundbl. det. O. Lundblad" (NHRS).

Other material. $3 \delta^{\star}, 3 q$ (brach.), west Malaysia: Ulu Gombag FSC, Alt 1, 8. 10. 1986, leg. D. Kovac (FSFM, UBCB); $2 \hat{\jmath}$, (brach.) West Malaysia: Ulu Gombag FSC, Sungai Gombag, A 70 , 30.iv.1998, leg. D. Kovac (FSFM); $1 \delta$ (brach.) Singapore: NUS, Botany Garden, $\mathrm{S}_{1}, 31 . x .1990$, leg. H.K. Lua (FSFM); $20,1 \%$ (brach.) Singapore: Seletar Reservoir Park, $\mathrm{S}_{3}$, $\mathrm{S}_{4}$, 12.-16.v.1994 leg. H.K. Lua (FSFM); 4خे, $1 \uparrow$ Malaysia, Sarawak Umg. Kuching Bako NP, 21.ii.1993, leg. M. Jäch (10) (NHMW, UBCB); 10 Malaysia: Sarawak Bako NP, N Kuching 21.-22.ii.1993 leg. H. Zettel (8) (NHMW); 2 \% (brach.) Indonesia: Kalimantan Apokayan, Long Ampung Lidung Payau, Sungai Sungan 28.xii.1997, leg. Mazzoldi (CZVA).

Distribution. Sumatra; Borneo (Sarawak, Kalimantan), Singapore, southern area of peninsular Malaysia.

TABLE 1. Some morphometrical characters of males of $I$. chinai. a/b - ratio: length of apical club-shaped process of aedeagus/width of the same structure (see also Fig. 1); angle $\delta$ - angle between longitudinal axis of the club-shaped process and longitudinal axis of the subapical narrowed part of aedeagus (see also Fig. 2).

\begin{tabular}{lcccc}
\hline \multirow{2}{*}{ Characters } & \multicolumn{3}{c}{ Material from } \\
\cline { 2 - 5 } & Sumatra & Sarawak & Singapore & W. Malaysia \\
\hline Body length & $1.30-1.36$ & $1.30-1.43$ & $1.40-1.49$ & $1.38-1.54$ \\
a/b & 2.0 & $2.60-2.66$ & $2.00-2.10$ & $2.50-2.60$ \\
Angle $\delta$ & $5^{\circ}$ & $20^{\circ}$ & $14^{\circ}$ & $14-20^{\circ}$ \\
\hline
\end{tabular}



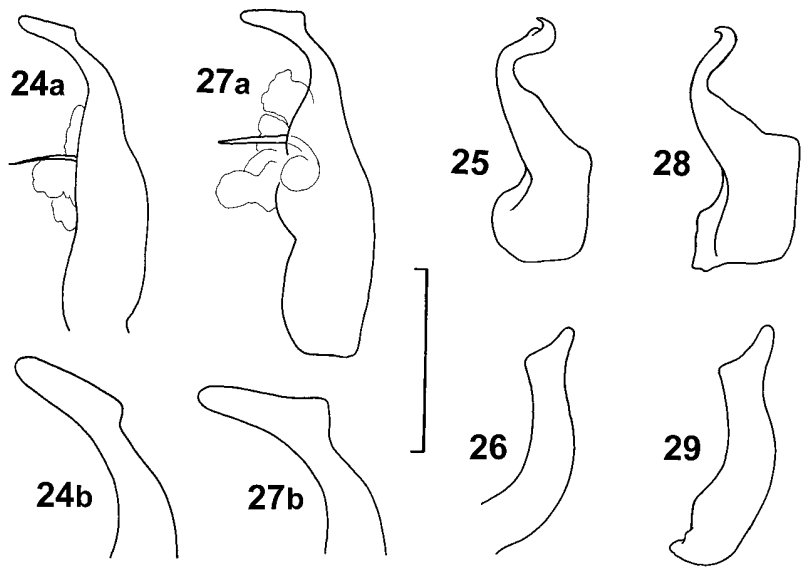

Figs 24-29: Male genitalia of Idiotrephes polhemusi (24-26) and I. yupae (27-29). 24, 27 - aedeagus; 25, 28 - left paramere; 26,29 - right paramere. Scale bar: $0.2 \mathrm{~mm}(0.1 \mathrm{~mm}$ for Figs 24b, 27b).

Habitats. See Lundblad (1933); specimens from peninsular Malaysia from ponds and lithotelms (Kovac \& Yang, 1990); specimens from Sarawak from very acidic shallow water bodies.

\section{Idiotrephes asiaticus sp. $\mathbf{n}$.}

Idiotrephes chinai: Papáček 1994: 423; Zettel 1994: 167 (partim); Papáček 1995: 110.

Diagnosis. Body usually small (Table 3); tip of mesosternal carina pointing anteriad, metasternal carina pointing mostly posteriad. Body length of micropterous morph 1.27-1.52 mm; macropterous morph 1.36-1.63 $\mathrm{mm}$.

Male: Aedeagus with relatively long distal part, apex elongate, subparallel; angle $\delta 40-50^{\circ}$, somewhat variable in different specimens and populations (see Tables 2, 3, and Figs 18,21). Left paramere with subrectangular basal part and slender distal part (Figs 19, 22); right paramere distally broad, apex obliquely truncate (Figs 20,23).

Female: Abdominal sternum 7 with simple deep incision, only rarely some specimens also with J-shaped impression (compare Figs 31a, b). First left valvifer with posterolateral lobe, first valvulae with produced posterior corners (Fig. 55).

Comparative notes. Similar to $I$. chinai, but aedeagus with shorter tip and larger angle $\delta$; first valvulae larger than in I. chinai, posterior corner of first valvulae produced in I. asiaticus, rounded in I. chinai (compare Figs $54,55)$.

Type material. Holotype (brach. o): "Vietnam: Dong Nai Pr. Nam Cat Tien NP (42) Dong Nai Riv., lithotelms 19.6.1995, leg. M. Papáček" (NHMW). Paratypes: 10§, 10 (brach.), 10 ,

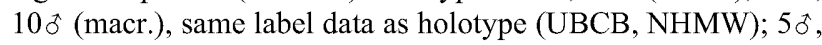

5 q (brach.) Vietnam: Hanoi, ceramic bonsai-bowls, 15.5.1995, leg. M. Papáček (UBCB); 1 ㅇ (brach.) "Thailand: Mae Hong Son Prov. $13 \mathrm{~km}$ SE Mae Hong Son 13.11.1995 leg. H. Zettel (14b)" (NHMW); 15॰, 11ㅇ (brach.), 1ㅊ, 2 ㅇ (macr.) "Thailand: Chiang Mai Prov. W Mae Rim, Mae Sa NP Mae Sa Falls, 30.-31.10.1995, leg. H. Zettel (2)" (CNTN, JTPC, KKUA, NHMW, UBCB,); $1 \delta$ (brach.) Thailand: Chiang Mai Prov., Doi Inthanon N.P., Mae Ya Waterfall, $D_{37}$ 1.12.1996, leg. D. Kovac (FSFM); 5oे, 3 ㅇ (macr.) "Thailand Phitsanulok Prov. Tung Saleangluang NP $300 \mathrm{~m} 101 \mathrm{~km}$ E Phitsanulok, 17.XI.1994, leg. Chen \& Piyapichart" (CPCB, NHMW); 20 (brach.) "Thailand: Phetchabun Prov. Nam Nao NP, Huai Phrom Laeng, 24.11.1995 leg. H. Zettel (22)" (NHMW); 10 (macr.) "Thailand: Khon Kaen Prov. 30 km NNW Khon Kaen Nam Pong, nr. Ban Hua Phu 20.11.1995, leg. Zettel (19)" (NHMW); 13 0,13 (brach.), 4 5 , 7 (macr.) "Thailand: Khon Kaen Prov. Phu Phan Kham NP, Ban Noon Hua Chang, Huai Sam Caen 21.11.1995, leg. H. Zettel (20a)" (NHMW, UBCB, KKUA, CSS); 1 \%, 2 \% (brach.), 10,2 (macr.) leg. N. Nieser (same locality data as leg. Zettel 20a) (CNTN); $4 \lesssim$ (macr.), $1 \%$ (brach.) "Thailand: Khon Kaen Prov. Phu Phan Kham NP, Ban Noon Hua Chang, Huai Sam Caen 21.11.1995, leg. H. Zettel (20b)" (NHMW).

Other material. $3 \hat{t}$ (brach.), $1 \hat{\delta}, 1$ क (macr.) leg. Nieser N9523 (same locality data as leg. Zettel 20b) (CNTN); 10 (brach.), 1 ㅇ (macr.) "Thailand: Khon Kaen Khon Kaen University concrete water tanks 7.4.1994, leg. W.D. Shepard" (NHMW, CSS); 1 ( (brach.), 10 , 1 ㅇ (macr.) "Thailand: Sakhon Nakhon 11 km NE Ban Kham Poem Huai Ya, 5.III.1994 leg. W.D. Shepard (1027)" (NHMW); 5o, 4우 (brach.) "Thailand: Satun Thale Ban NP, Bach (= stream) Ya Roi Wasserfall (= waterfall) 3.3.1994, leg. M. Madl" (NHMW, UBCB); 5 §, 5 ㅇ. (brach.) Thailand: Khlong Lan, Namla Waterfall, seeping rock and lithotelms, $\mathrm{Aq}_{77}, \mathrm{Aq}_{78}, 13 .-14.9 .1998$, leg. D. Kovac (FSFM); $3{ }^{\star}, 3$ q (brach.) West Malaysia: Sungei Kinchin, rockpools, Alt 6 , Alt, , 17. and 23.5.1988, leg. D. Kovac (FSFM); $2 \hat{\jmath}$, 2 o (brach.) West Malaysia: Ulu Gombag, pond, $\mathrm{Aq}_{20}$, leg. D. Kovac (FSFM).

Etymology. Named after its distribution over a large area of mainland of southeast Asia.

Distribution. Vietnam: Dong Nai, Hanoi; Thailand: Mae Hong Son, Chiang Mai, Phitsanulok, Phetchabun, Khon Kaen, Sakhon Nakhon, Satun; west Malaysia: Pahang, Selangor.

Habitats. Idiotrephes asiaticus sp. $\mathrm{n}$. is a eurytopic species, which can be found in a wide variety of stagnant and lentic waters. It is known from small lithotelms, some less than a halfmeter in diameter, in Chiang Mai Province (leg. Zettel, no. 2) and Nam Cat Tien N. P. in Dong Nai Province (leg. Papáček); from seeping rocks in Khlong Lan, Namla waterfall (leg. Kovac); from the edges of lentic areas of a small stream in Phetchabun Province (leg. Zettel, no. 22); from the lentic sides of a large river in Khon Kaen Province (leg. Zettel, no. 19); from a very shallow, nearly stagnant stream, whose bottom is covered with algae in Khon Kaen (no. 20a, b); from concrete water tanks in the Khon Kaen University campus (leg. Shepard); and also from bonsai ceramic bowls in Hanoi, Vietnam (leg. Papáček).

TABLE 2. Some morphometrical characters of males of $I$. asiaticus. Explanation of abbreviations as in Table 1.

\begin{tabular}{|c|c|c|c|c|c|}
\hline \multirow{3}{*}{ Character } & \multicolumn{5}{|c|}{ Material from (area/prov.) } \\
\hline & $\overline{\text { Vietnam }}$ & Thailand (NE) & Thailand $(\mathrm{N})$ & Thailand (S) & W Malaysia \\
\hline & Dong Nai & Khon Kaen & Phitsanulok & Satun & Pahang \\
\hline$\overline{\mathrm{a} / \mathrm{b}}$ & $2.64-3.10$ & $2.20-2.30$ & $3.00-3.20$ & $3.0-3.15$ & $2.70-2.95$ \\
\hline Angle $\delta$ & $44-46^{\circ}$ & $43-46^{\circ}$ & $45-50^{\circ}$ & $40-46^{\circ}$ & $42-48^{\circ}$ \\
\hline
\end{tabular}




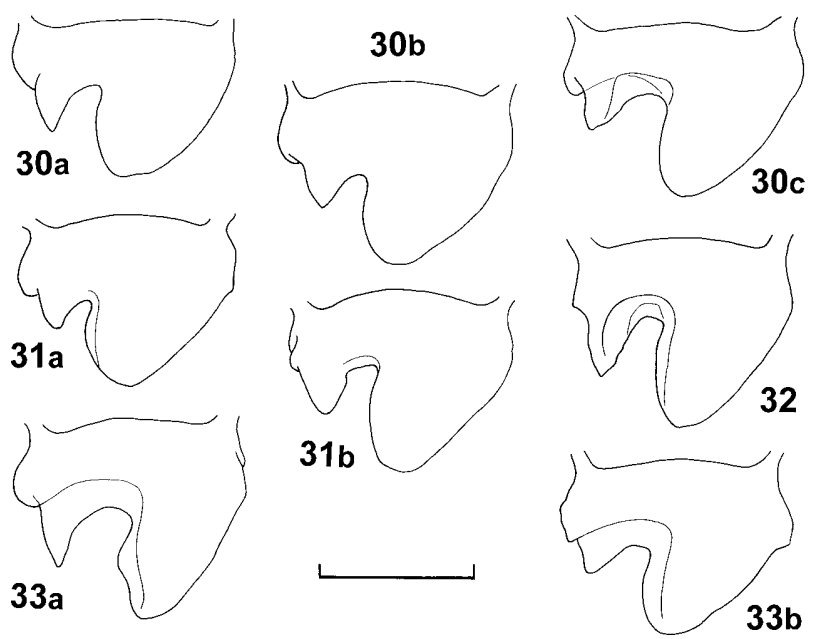

Figs 30-33: Female abdominal sternum 7 in Idiotrephes chinai group. $30-I$. chinai from Sumatra (a), Kalimantan (b), Sarawak (c); $31-I$. asiaticus from Nam Cat Tien N. P. (a), Khon Kaen (b); 32 - I. polhemusi; 33 - I. yupae from Chiang Mai (a) and Khlong Lan (b). Scale bar: $0.5 \mathrm{~mm}$.

\section{Idiotrephes polhemusi sp. $\mathbf{n}$.}

Idiotrephes chinai: Zettel 1994: 167 (partim).

Diagnosis. Body length rather variable compared with other Idiotrephes spp. (see Table 3); prosternal carina with two obtuse tips, each more or less quadrangular; tip of mesosternal carina oriented posteriad (Fig. 64).

Male: Apex of aedeagus subparallel, relatively long, angle $\delta 30-35^{\circ}$ (Fig. 24). Left paramere (Fig. 25) with preapical swelling, right paramere (Fig. 26) with short rounded tip.

Female: Abdominal sternum 7 with simple deep roundly subtrapezoidal incision and large J-shaped impression with break-lined margin (Fig. 32); two groups of thick bristles on surface of this incision. Complex of first valvifers and valvulae relatively large (Fig. 56) (see also relative morphometrical characters in Table 3). First left valvula with conspicuous posteriad pointing produced caudal corner, first right valvula only with roundly obtuse caudal corner.

Comparative notes. Close to I. asiaticus sp. n. Female abdominal sternum 7 somewhat similar to that of I. yupae sp. n., also with distinct long hair (bristles) tuft at bottom of impression, but with less distinct ridge. Tip of aedeagus longer than in $I$. asiaticus, less acute than in $I$. yupae. Left paramere not forming a right angle at end of base as in I. yupae, more similar to that of I. asiaticus, but with diagnostic preapical swelling.

Type material. Holotype (brach. đ): “Thailand 1990 (14) Prov. Rayong Khao Chamao NP leg. Jäch 12.-13.12." (NHMW); paratypes: 10,3 우 (macr.), same label data as holotype (NHMW, UBCB).

Etymology. This species is named in honour of Dr. John T. Polhemus (Englewood, Colorado), outstanding heteropterist, to celebrate his 70th birthday.

Distribution. Thailand: Rayong.

Habitats. No details on the habitats are known.

\section{Idiotrephes yupae sp. $\mathbf{n}$.}

Diagnosis. Medium- to large-sized species; punctuation reduced (especially in brachypterous morph); meso- and metasternal carinae pointing posteriad (Fig. 65).

Male: Aedeagus (Fig. 27) with elongate distal part, apex narrowly triangular, angle $\delta$ greater than $50^{\circ}$. Left paramere (Fig. 28) with rectangular basal part and very slender distal part; right paramere (Fig. 29) distally rather broad, apex obliquely truncate.

Female: Abdominal sternum 7 with large simple incision and impression lined anteromesally with conspicuous ridge (Figs 33a, b). Two groups of thick bristles at bottom of impression. Complex of first valvifers and valvulae large. Lateroposterior margin of first right valvula with small inconspicuous wide lobe.

Comparative notes. Similar to $I$. asiaticus sp. n., but larger; female abdominal sternum 7 with more distinct break-like ridge and well developed obliquely directed tuft of hairs (bristles) at bottom of impression. Male aedeagus with more bent (dorsal outline of apex nearly rectangular to longitudinal axis of aedeagus) and more acute apex; differing from other $I$. chinai-group species by the larger angle $\delta$. Left paramere basally stouter, and its shape also conspicuously different from that of $I$. polhemusi.

Type material. Holotype (macr. $\sigma^{\star}$ ): "Thailand: Chiang Mai Prov. Doi Inthanon NP, Mae Klang, Falls 4.11.1995 leg. H.

Table 3. Comparison of some morphometrical characters of Idiotrephes spp. a/b - ratio: length of apical club-shaped process of aedeagus/width of the same structure (see also Fig. 1); angle $\delta$ - angle between longitudinal axis of the club-shaped process and longitudinal axis of subapical narrowed part of aedeagus (see also Fig. 2); a/vl - ratio: length of apodeme of the first valvula/length of the first valvula; vl/vw - ratio: length of the first valvula/width of the same structure (see also Fig. 3 ).

\begin{tabular}{lccccc}
\hline Species & Body length & $\mathrm{a} / \mathrm{b}$ & Angle $\delta$ & $\mathrm{al} / \mathrm{vl}$ & $\mathrm{vl} / \mathrm{vw}$ \\
\hline I chinai-group & & & & & \\
$\quad$ I. chinai & $1.30-1.54$ & $2.00-2.66$ & $5-20^{\circ}$ & $1.63-1.75$ & $1.26-1.45$ \\
$\quad$ I. asiaticus & $1.27-1.63$ & $2.30-3.21$ & $40-50^{\circ}$ & $1.50-1.70$ & $1.55-1.63$ \\
I. polhemusi & $1.30-1.66$ & $3.10-3.25$ & $30-35^{\circ}$ & $1.95-2.00$ & $1.32-1.38$ \\
$\quad$ I. yupae & $1.50-1.70$ & $3.70-4.00$ & $50-52^{\circ}$ & $2.10-2.20$ & $1.42-1.44$ \\
I. maior-group & & & & & \\
$\quad$ I. maior & $1.50-1.60$ & $1.88-2.10$ & $42-48^{\circ}$ & $1.61-1.70$ & $1.12-1.20$ \\
I. meszarosi & $1.45-1.49$ & $2.00-2.10$ & $60-63^{\circ}$ & $1.76-1.80$ & $1.10-1.19$ \\
$\quad$ I. hainanensis & $1.38-1.39$ & $2.60-2.66$ & $60-62^{\circ}$ & $1.38-1.45$ & $1.98-2.04$ \\
I. thai-group & & & & & \\
$\quad$ I. thai & $1.47-1.78$ & $0.83-1.20$ & $90^{\circ}$ & $1.70-1.78$ & $1.35-1.38$ \\
I. shepardi & $1.55-1.76$ & - & $110^{\circ}$ & & 1.63 \\
\hline
\end{tabular}




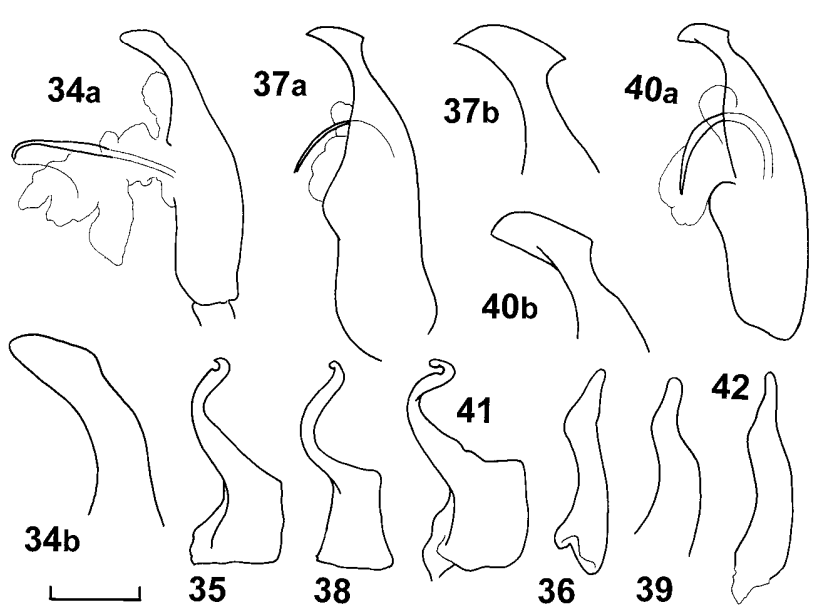

Figs 34-42: Male genitalia of Idiotrephes maior group. 34-36 -I. maior; 37-39 - I. meszarosi; 40-42 -I. hainanensis. 34, 37, 40 - aedeagus; 35, 38, 41 - left paramere; 36, 39, 42 - right paramere. Scale bar: $0.1 \mathrm{~mm}(0.05 \mathrm{~mm}$ for Figs $34 \mathrm{~b}, 37 \mathrm{~b}, 40 \mathrm{~b}$, respectively).

Zettel (6)" (NHMW). Paratypes: 3ठ, $3 q$ (macr.), 1 (brach.), same label data as holotype (NHMW, UBCB, KKUA).

Other material. $1 \delta, 2 q$ (brach.) Thailand: Khlong Lan, Namla Waterfall, seeping rock and lithotelms, $\mathrm{Aq}_{79}, 14.9 .1998$, leg. D. Kovac (FSFM).

Etymology. This species is named in honour of Prof. Yupa Hanboonsong (Khon Kaen University) for her help and hospitality to the second author during his stay in Thailand and for her contributions to the knowledge of Thai insects.

Distribution. Thailand: Chiang Mai, Khlong Lan.

Habitats. The type locality is a shallow, rather large inundation pool on the banks of the Mae Klang Waterfalls. Idiotrephes yupae sp. $\mathrm{n}$. was also found in a small lithotelm and on the seeping rock in the Namla Waterfall.

\section{The Idiotrephes maior group}

The group contains three species, two from Vietnam and one from the zoogeographically closely related island of Hainan (south China). Important characters of the group are: (1) distal part of aedeagus (distal of opening) relatively short (compared to I. chinai group); (2) distal part of right paramere slender and tapered, apex acuminate; (3) incision of female abdominal sternum 7 small; (4) break-like ridge of female abdominal sternum 7 complete, usually strongly developed; (5) size medium to large (see Table 3). Differences among species are mainly found in the tip of the aedeagus and in the shape of the left paramere, small differences also occur in the female abdominal sternum 7, and complex of first valvulae and first valvifers.

\section{Idiotrephes maior Papáček, 1994}

Idiotrephes maior Papáček, 1994: 419.

Diagnostic notes. Large species; metasternal carina pointing posteriad (Fig. 66).

Male: Aedeagus (Fig. 34) with elongate distal part, apex relatively short. Left paramere (Fig. 36) with nearly rectangular basal part and slender distal part; right paramere (Fig. 35) distally narrow, apex acute.
Female: Abdominal sternum 7 with small incision and impression margined by L-shaped break-like ridge (Fig. 49). First valvifers large, broad; lateral margin of left valvifer posteriorly with small incision. Posterior corners of first valvulae in form small rounded lobes (Fig. 58).

Comparative notes. Idiotrephes maior clearly differs from other species of the I. maior-group by the tip of aedeagus and the shape of the first valvulae; from species of the I. chinai-group by the short apex of aedeagus, the incision of female abdominal sternum 7, and by the size and shape of the first valvifers and valvulae.

Type material. Holotype (brach. \&): Vietnam, Hanoi, Temple of Literature and Pagoda (Temple) on Islet in Hoan Kiem Lake, 30.x.1985, leg. T. Soldán (UBCB). Paratypes: All from Vietnam: Hanoi: $1 \delta$ (brach., legs missing), 1 ㅇ (brach.; brach. hindwings), 19.xi.1989, leg. T. Soldán; 19 (brach.), 30.ix.1989, leg. M. Tonner (UBCB); 10 (brach.) 15.v.1995, leg. M. Papáček (UCBC).

Distribution. Vietnam: Hanoi.

Habitats. Specimens of $I$. maior were caught in a bonsaibowl and in a small pond.

\section{Idiotrephes meszarosi Papáček, 1995}

Idiotrephes meszarosi Papáček, 1995: 105.

Diagnostic notes. Medium-sized species; tip of mesosternal carina oriented posteriad, metasternal carina with rounded lobe pointing posteriad (Fig. 67).

Male: Aedeagus with diagnostic ax-like pointed apex (Fig. 37). Parameres see Figs 38, 39.

Female: Abdominal sternum 7 with three small round incisions and impression emarginated by incomplete L-shaped break-like ridge (Fig. 50). Complex of first valvifers and valvulae large, broad. First valvulae tightly joined with valvifers; lateroposterior margin of valvifers continue into margins of valvulae. Posterior corners of valvulae without lobes or tips (Fig. 59).

Comparative notes. Idiotrephes meszarosi differs from other Idiotrephes species by the ax-like apex of the aedeagus and by broad simple first valvifers and first valvulae.

Type material. Holotype (brach. §): Vietnam, $10 \mathrm{~km} \mathrm{~W}$ of Than Lôc (SWW of Hanoi, on the way between Hanoi and Moc Chau), 27.x.1986, leg. Meszáros \& Vasárhelyi (UBCB). Paratypes: $1 \delta, 2$ ㅇ, (brach.), slide mounted, same label data as holotype (UBCB).

Distribution. Vietnam: "Than Lôc", SWW of Hanoi.

Habitats. Specimens were collected in and on the water of a stream.

\section{Idiotrephes hainanensis sp. $\mathbf{n}$.}

Diagnosis. Small species; mesosternal carina pointing posteriad, mesosternal carina with obtuse posterior corner (Fig. 68).

Male: Aedeagus (Fig. 40) with elongate distal part, shoe-shaped apex short, exposed part of vesica prominent. Left paramere with rectangular basal part and very slender distal part (Fig. 42); right paramere (Fig. 41) distally narrow, apex acute.

Female: Abdominal sternum 7 with small shallow double incision and impression bordered by incomplete 

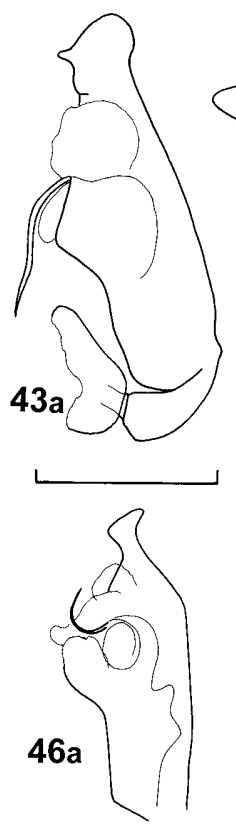
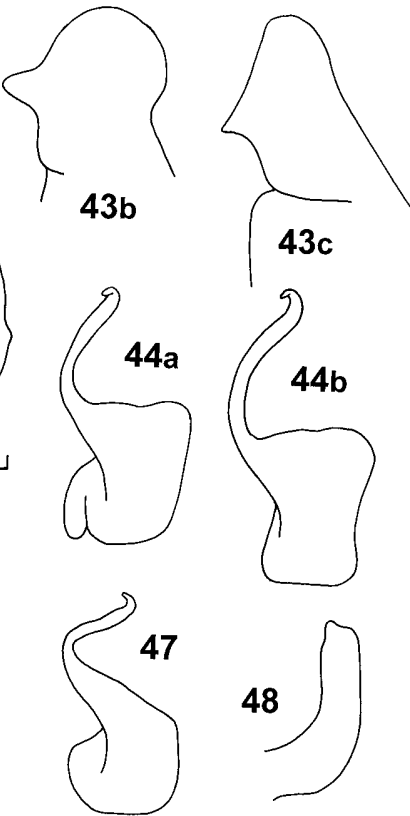
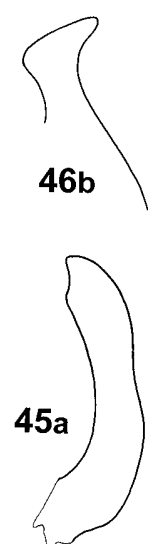

$45 b$
Figs 43-48: Male genitalia of Idiotrephes thai group. 43-45 I. thai (a, b, c - demonstrating variability; $44 \mathrm{~b}$ - with broken basal part); 46-48 - I. shepardi. 43, 46 - aedeagus; 44,47 - left paramere; 45,48 - right paramere. Scale bar: $0.2 \mathrm{~mm}(0.1 \mathrm{~mm}$ for Figs 43b, c, 46b, respectively).

L-shaped break-like ridge (Fig. 51). First valvulae very narrow (Fig. 60).

Comparative notes. Idiotrephes hainanensis differs distinctly from all other Idiotrephes species by the apex of the aedeagus (similar to aedeagus of $I$. meszarosi but apex laterally flattened in I. meszarosi, and evidently three-dimensional in I. hainanensis), and by the very narrow first valvulae of females.

Type material. Holotype (brach. 8 ): "China: Hainan (204) 4 km E Jianfeng, 150 m Jianfeng Mt., 1996 22.-24.1., Ji \& Wang” (NHMW); paratypes (all brach.): $7 \delta 5$, same label data as holotype (NHMW, CASS, CPC, UBCB); 10, 1\% "China: Hainan (182) $10 \mathrm{~km}$ SW Qionghai, $20 \mathrm{~m}$ Baishiling, 14.1.1996, leg. Ji \& Wang" (NHMW).

Etymology. Named for the distribution in Hainan Island.

Distribution. China: Hainan.

Habitats. No information available.

\section{The Idiotrephes thai group}

The group presently contains two species, I. thai $\mathrm{sp} . \mathrm{n}$. and $I$. shepardi sp. n. from north and northeast Thailand, which are well characterized by the following characters: (1) tip of the aedeagus not elongate, apically rounded, and with a more or less developed tooth; (2) apex of the right paramere nearly transversely truncate or rounded; (3) distal part of left paramere very slender; (4) female abdominal sternum 7 without distinct incision, with weak shallow emargination only; (5) size relatively large (see Table 3). The two species are easy to separate by the male genitalia and the female abdominal sternum 7 .

\section{Idiotrephes thai sp. $\mathrm{n}$.}

Diagnosis. See group diagnosis; tip of mesosternal and metasternal carinae oriented posteroventrally (Fig. 69).

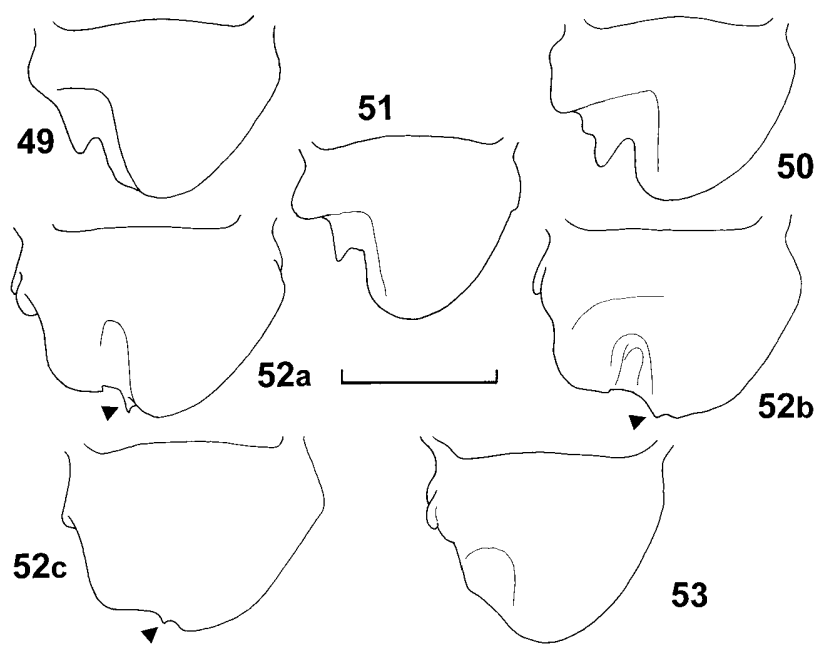

Figs 49-53: Female abdominal sternum 7 of Idiotrephes maior (49-51) and $I$. thai (52-53) groups. $49-I$. maior; $50-I$. meszarosi; 51 - I. hainanensis; $52-I$. thai from Phu Phan Kham N. P. (a, b), and from Sakhon Nakhon (c); 53 - I. shepardi. Scale bar: $0.5 \mathrm{~mm}$.

Male: Apex of aedeagus short, shaped like human head in profile (Figs 43a, b). Left paramere (Fig. 44) with small anteroapical incision. Right paramere (Fig. 45) with subtle S-shaped distal part and suboblong proximal part.

Female: Abdominal sternum 7 with small posteriorly directed tip of hind margin, and impression lined by $\mathrm{J}$-shaped break-like ridge in some specimens (Figs 52a, b) or without ridge (Fig. 52c). First valvifers and valvulae relatively narrow but robust (Fig. 61); their lateral outline simple, without any lobes or incisions.

Comparative notes. Idiotrephes thai differs from all other Idiotrephes species by the human head-like apex of the aedeagus, and relatively narrow but robust first valvifers and valvulae.

Type material. Holotype (brach. ô): "Thailand: Khon Kaen Prov. Phu Phan Kham NP, Ban Noon Hua Chang, Huai Sam Caen 21.11.1995, leg. H. Zettel (20a)" (NHMW). Paratypes: 30 , 5 ㅇ (brach.), 2 ㅇ (macr.), same label data (NHMW, CSS, UBCB); 10 (macr.) "Thailand: Petchabun $21 \mathrm{~km}$ SE Nakon Thai 27 III 1994 Pa Lad Waterfall WDS-A-1048, William D. Shepard leg." (NHMW); 19 (macr.) "Thailand: Sakhon Nakhon $11 \mathrm{~km}$ NE Ban Kham Poem Huai Ya, 5.III.1994 leg. W.D. Shepard (1027)" (NHMW).

Other material. 1 i (brach.) Thailand: Khon Kaen Prov. Phu Pham Kham NP, Ban Noon, Hua Chang, Huai Sam Caen, leg. N. Nieser N9522 (CNTN).

Etymology. This species is named after the country of its origin, Thailand, which is so extremely diverse in different clades of Helotrephidae.

Distribution. Thailand: Phetchabun, Sakhon Nakhon, Khon Kaen.

Habitats. The type locality is a small stream in a quite open area with degraded forests. The stream is extremely slowly flowing and shallow where the specimens were found. The limestone bottom forms small connected pools and is thickly covered with algae due to the open, unshaded conditions. Idiotrephes thai $\mathrm{sp}$. $\mathrm{n}$. was found on the bottom of the stream intermixed with $I$. asiaticus sp. n. 


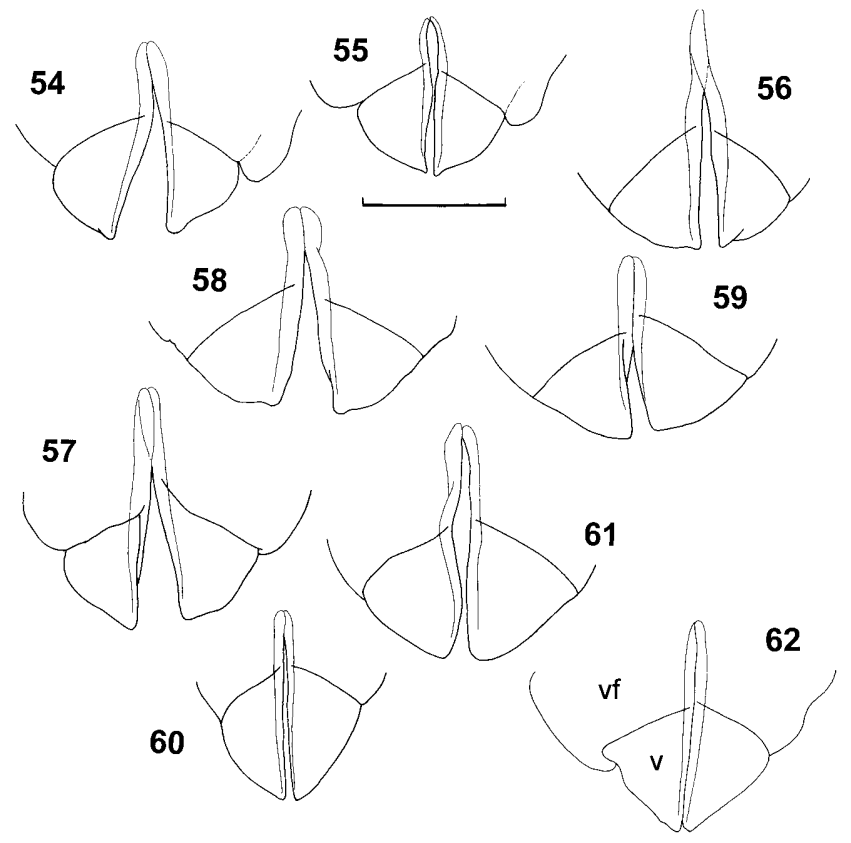

Figs 54-62: Complex of the first valvifers (caudal parts only in some cases) and first valvulae in Idiotrephes species. Idiotrephes chinai group: 54 - I. chinai; 55 - I. asiaticus; $56-I$. polhemusi; 57 - I. yupae. Idiotrephes maior group: 58 - I. maior; 59 -I. meszarosi; $60-I$. hainanensis. Idiotrephes thai group: 61 I. thai; $62-I$. shepardi. $\mathrm{v}-$ the first valvula, $\mathrm{vf}-$ the first valvifer. Scale bar: $0.2 \mathrm{~mm}$.

\section{Idiotrephes shepardi sp. $\mathrm{n}$.}

Diagnosis. See group diagnosis; prosternal carina with posteroventral incision, tip of mesosternal carina oriented ventrad, metasternal carina pointing posteriad (Fig. 70).

Male: Aedeagus with relatively short distal part, apex recurved and pointed (Fig. 46). Left paramere (Fig. 47) with rectangular basal part and very slender distal part; right paramere (Fig. 48) distally broad, apex truncate.

Female: Abdominal sternum 7 without incision, but with small, shallow impression (Fig. 53). First valvulae broad; lateral margins of first left valvifer and first right valvula with distinct incisions (Fig. 62).

Comparative notes. Idiotrephes shepardi differs from all other Idiotrephes species by the caudally recurved apex of the aedeagus of males, and by the anterolateral incision of the first right valvula in females.

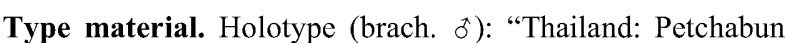
Nam Nao NP, Prom Laeng 22.III.1994 leg. W.D. Shepard (1040)" (NHMW); paratypes: 13\%, $13 q$ (brach.), 5o, 4ㅇ (macr.), same label data as holotype (NHMW, CSS, UBCB); 20, 7 ㅇ (brach.) "Thailand: Phetchabun Prov. Nam Nao NP, Huai Phrom Laeng, 24.11.1995 leg. H. Zettel (22)" (NHMW, KKUA)

Etymology. Named in honour of Prof. William D. Shepard (Sacramento), who provided us with numerous interesting Helotrephidae collected in Thailand and Malaysia.

Distribution. Thailand: Phetchabun.

Habitats. The type locality is a rather small stream slowly flowing through a mountainous pine forest in the Nam Nao National Park. Specimens were collected by the second author along the edges of lentic areas of this stream.
63

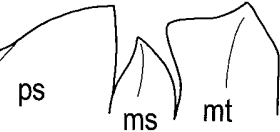

64
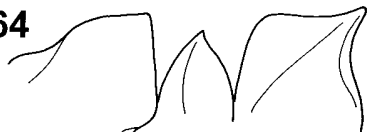

65

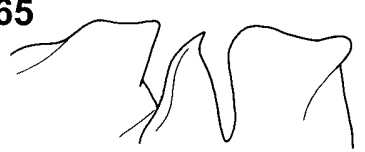

66
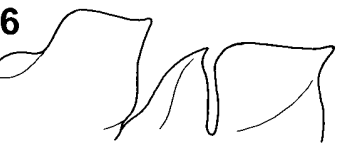

67

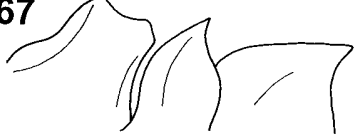

68

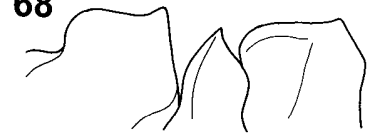

69

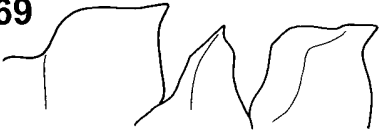

70

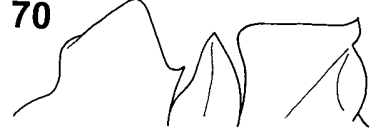

Figs 63-70: Diagrammatic examples of most frequented outlines of ventral midsternal thoracic carinae in Idiotrephes species. Right lateral view (venter up). 63 - I. chinai (I. asiaticus differs mostly only by posteriad pointed metasternal carina); 64 -I. polhemusi; 65 - I. yupae; 66 - I. maior; $67-I$. meszarosi; $68-I$. hainanensis; $69-$ I. thai; $70-I$. shepardi. ps, ms, and $\mathrm{mt}$ - pro-, meso-, and metasternal carinae respectively.

\section{DISCUSSION}

\section{Distribution, discrimination of species, interspecific similarities, and relationships}

We do not yet have any information about the occurrence of Idiotrephes in Java. Also, several expeditions by the second author failed to find this species in the Philippines, although its occurrence in Palawan seems possible. No Idiotrephes species are known to us from Burma, Laos, and Cambodia.

Two species are most abundant and widely distributed in southeast Asia, I. asiaticus (on the mainland) and $I$. chinai (in the Indomalayan archipelago); they are sympatric in the southern part of west Malaysia. Both species have many morphological similarities and variable characters. After analysing the material of these species, two controversial hypotheses appeared: (1) the material represents only one species with series from somewhat different and variable local populations; (2) the material represents two species, each with somewhat different and variable local populations. Detailed study of the morphology of terminalia (especially apex of aedeagus, and shape of posterior corners of the first valvulae) in relatively large series of specimens from different areas, morphometrical characters (especially angle $\delta$, and vl/vw ratio), as well as the sympatric occurrence of two distinct morphospecies (without intermediate forms) in peninsular Malaysia, evidently support the second hypothesis. We have not had any possibility to verify this hypothesis from the biological or genetical points of view, but in our opinion $I$. asiaticus and $I$. chinai are good species, not merely arbitrarily separated taxa.

Other species have smaller areas of distribution than $I$. asiaticus and I. chinai. Except I. hainanensis, they live mainly sympatrically with $I$. asiaticus. Their relationships 


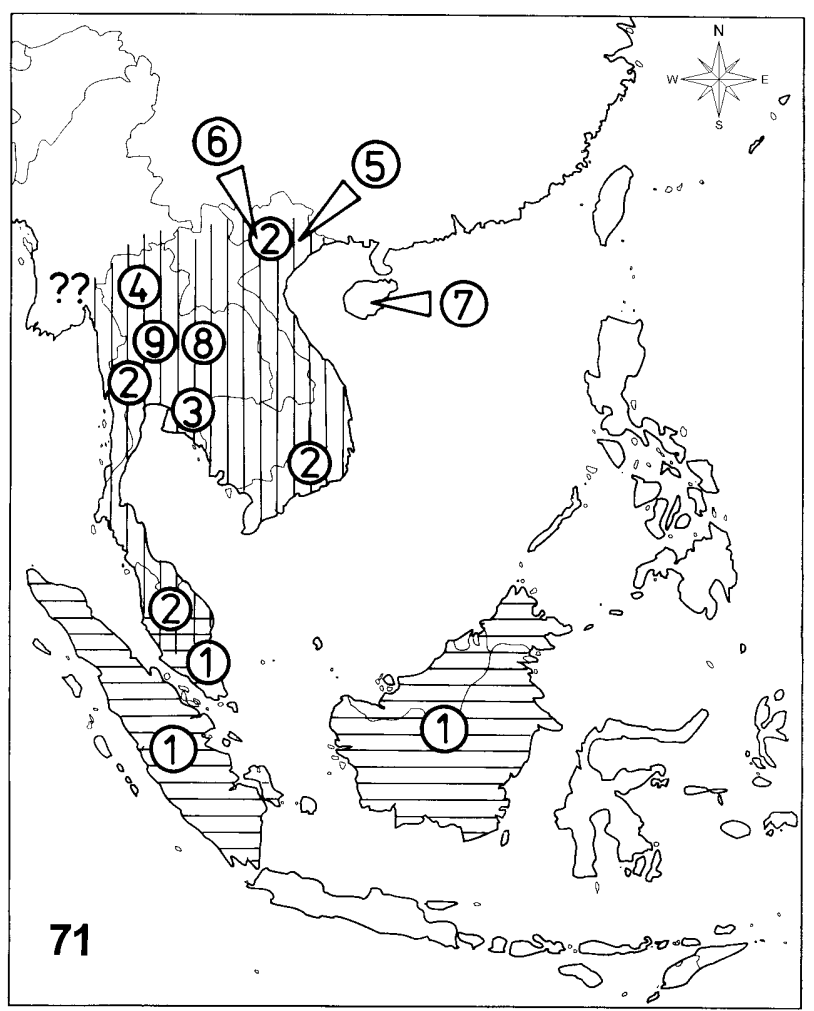

Fig. 71: Distribution of Idiotrephes species in the Southeast Asia. 1 - I. chinai; 2 - I. asiaticus (sympatric also with 3, 4, 8, 9 in central and north Thailand, 5, 6 in Vietnam); $3-I$. polhemusi; 4 - I. yupae; 5 -I. maior; $6-I$. meszarosi; 7 -I. hainanensis; $8-I$. thai; $9-I$. shepardi. Vertically lined area supposed range of $I$. chinai; horizontally lined area - supposed range of $I$. asiaticus; ?? - uncertainty of the western and northern border of I. asiaticus distribution.

are indicated by characters (synapomorphies) presented in species-group diagnoses.

\section{Intergeneric similarities}

Papáček et al. (1989) noted some similarities of the genus Mixotrephes with other genera of Limnotrephini. It is necessary to make one correction (1) and to add two new similarities (2 and 3 ) to this previous paper, comparing also Mixotrephes with Idiotrephes. (1) More genera of Limnotrephini (e.g., Distotrephes, Mixotrephes, Idiotrephes) include species with slightly or conspicuously asymmetrical female abdominal sternum 7 (cf., e.g., Papáček et al., 1989; Zettel, 1995, 1999; this study). Idiotrephes thai and I. shepardi have only slightly asymmetrical sterna, without a deep incision. It is questionable to use symmetry or asymmetry of this sclerite as a character distinguishing particular genera. (2) Idiotrephes and Mixotrephes have very similar architecture and shape of the complex of the first valvifers and valvulae. Species of both genera have shortened first valvulae, shorter than its apodeme. (3) Both Idiotrephes and Mixotrephes species inhabit ephemeral waters.

\section{Key to the species of Idiotrephes}

1 Female ........................ 2

- Male ........................ 10
2 Abdominal sternum 7 without incision, only with weak emargination and with one or two shallow impressions (Figs $52,53)$; species from northern Thailand $\ldots \ldots \ldots \ldots 3$ Abdominal sternum 7 with small emargination or deep incision (e.g., Figs $30-33,49-51) \quad \ldots \ldots \ldots \ldots \ldots \ldots 4$

3 Abdominal sternum 7 with (a) shallow dextrocaudal emargination, (b) small, posteriorly directed tip of hind margin, localized near to medial line of sclerite (indicated by black arrows in Figs 52a, b, c), and (c) shallow impression and J-shaped break-like ridge (Figs 52a, b) or without ridge (Fig. $52 \mathrm{c}$ ); outer margins of first valvulae simple, without any lobes or incisions (Fig. 61) ................. thai Abdominal sternum 7 only with (a) small emargination posterolaterally, and (b) with impression, without any posteriorly directed marginal tip (Fig. 53); outer margin of first right valvula anteriorly with small incision (Fig. 62) .....

I. shepardi

4 Abdominal sternum 7 with deep incision (Figs 30-33), first left valvifer with conspicuous laterocaudal lobe ...... 5

- Abdominal sternum 7 with small emargination (Figs 49-51), first left valvifer without laterocaudal lobe ....... 8

5 Break-like ridge of abdominal sternum 7 strongly reduced, lacking or hardly traceable along medial margin of incision (Figs 30,31), tuft of hairs at bottom of incision usually not strongly developed; first valvulae small $\ldots \ldots \ldots \ldots 6$ Break-like ridge of abdominal sternum 7 relatively well developed, parallel with medial margin of incision (Figs 32, 33 ), at bottom of incision always with a tuft of long hairs; first valvulae large and broad (Figs 56, 57) (species from central and north Thailand) $\ldots \ldots \ldots \ldots \ldots \ldots \ldots$

6 First valvulae with sharp posterior corners (Fig. 55) (Southeast Asian mainland) $\ldots \ldots \ldots \ldots \ldots \ldots \ldots$. asiaticus First valvulae with round lobate posterior corners (Fig. 54) (Sumatra, Borneo, southern part of west Malaysia) ...... .................................. I. chinai

7 First valvulae with simple round posterior corners (Fig. 57) (North Thailand) $\ldots \ldots \ldots \ldots \ldots \ldots \ldots \ldots$ I. yupae First left valvula with prominent sharp posterior corner (Fig. 56) (central Thailand) ................ I. polhemusi

8 First left valvifer with small shallow lateroposterior incision (Fig. 58) ......................... I. maior First left valvifer without incision $\ldots \ldots \ldots \ldots \ldots 9$

9 First valvulae relatively broad (Fig. 59) ..... I. meszarosi First valvulae extremely narrow (Fig. 60) ........... .......................... I. hainanensis

10 Apex of aedeagus short, resembling human head or posteroapically with a more or less developed tooth (Figs 43, 46); apex of right paramere broadly rounded or with anteroapical incision (Figs 45, 48); left paramere with very slender distal part (Fig 44, 47 ) (species from northern Thailand) ........................... 11 - Genitalia different; apex of aedeagus slender, club- or axshaped (e.g., Figs 1, 18, 21, 34, 37), apex of right paramere slender or obliquely truncate (e.g., Figs 7, 20, 36, 42) . 12

11 Aedeagus robust; its apex short, subglobular, resembling human head (Figs 43a, b, c); right paramere robust, with anteroapical incision (Figs 45a, b) . . . . . . . . I. thai

- Aedeagus relatively small; tip of its apex directed posteriad (with posteroapical tooth) (Figs 46a, b); right paramere relatively short, with small apical round process ...I. shepardi

12 Apex of aedeagus ax-like, flat or three-dimensional (Figs

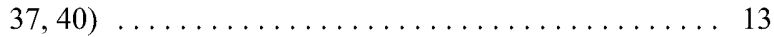

- Apex of aedeagus club-shaped (e.g., Figs 1, 5, 24) . . . 14

13 Apex of aedeagus laterally flattened (Figs 37a, b); right paramere S-shaped (Fig. 39) ............. I. meszarosi 
- Apex of aedeagus three-dimensional (Figs 40a, b); right paramere relatively straight (Fig. 42) (Hainan) ......... I. hainanensis

14 Apex of aedeagus mostly symmetrical or slightly asymmetrical, outline regularly round to ellipsoid; angle $\delta$ less than $20^{\circ}$ (see Fig. 2) (Figs 5, 8, 11, 14) . ......... I. chinai

- Apex of aedeagus asymmetrical; angle $\delta$ more than $20^{\circ} .15$

15 Apex of aedeagus short and robust (Figs 34a, b); right paramere nearly straight with tip pointing ventrally (Fig. 36) (north Vietnam) $\ldots \ldots \ldots \ldots \ldots \ldots \ldots \ldots$ I. maior

- Apex of aedeagus relatively long (Figs 18, 24, 27); tip of right paramere pointed distinctly posteriad or posteroventrad (e.g., Figs 20, 23, 26, 29) $\ldots \ldots \ldots \ldots \ldots \ldots 16$

16 Apex of aedeagus relatively short and wide (measurement $b$ - see Fig. 1) (Figs 18, 21) ................ I. asiaticus

- Apex of aedeagus relatively long and narrow (Figs 24, 27)

17 Apex of aedeagus: angle $\delta$ less than $35-40^{\circ}$ (Figs 24a, b) left paramere with anterior subapical (preapical) swelling (Fig 25) ...................... polhemusi

- Apex of aedeagus: angle $\delta$ about or more than $50^{\circ}$; distal part of left paramere without swelling (Fig. 28) . . I. yupae

ACKNOWLedGeMentS. M. Papáček thanks D. Kovac (Forschungsinstitut und Museum Senckenberg, Frankfurt am Main) for the possibility to study his collection and for the loan of some material of I. chinai, I. asiaticus, and I. yupae from west Malaysia and Thailand, and the Naturhistorisches Museum in Wien for the opportunity to study its helothrephid collection His research was supported by the Pedagogical Faculty, University of South Bohemia, and by the Grant Agency of the Czech Republic (grant No. 206/98/0160).

$\mathrm{H}$. Zettel thanks the following persons for loaning or leaving specimens for this study: P.P. Chen (CPCB, Beijing), M.A. Jäch (NHMW, Vienna), L. Ji (Shenyang, China), P. Lindskog (NHRS, Stockholm), M. Madl (Frauenkirchen, Austria), P Mazzoldi (Brescia, Italy), N. Nieser (CNTN, Tiel), S. Piyapichart (Naresuan University, Bangkok), W.D. Shepard (CSS, Sacramento), M. Wang (Shenyang, China); and those who endabled, supported, or eased his field trip to Thailand: $\mathrm{T}$. Jamjanya, Y. Hanboonsong, N. Sangpradub (all Khon Kaen University), P.P. Chen (CPCB), V. Naknan (Nam Nao NP), N Nieser, P. Schwendinger (Insbruck, Austria), and S. Wongsiri (Chulalongkorn University, Phitsanulok).

\section{REFERENCES}

Dickerson R.E., Merrill E.D. McGregor R.C., Schultze W., TAYlor E.H. \& Herre A.W. 1928: Distribution of Life in the Philippines. Monograph of the Bureau of Sciences No. 21. Manila, 322 pp., 42 plates.

Kovac D. \& YANG C.M. 1990: A preliminary checklist of the semiaquatic and aquatic Hemiptera (Heteroptera: Gerromorpha and Nepomorpha) of Ulu Kinchin, Pahang, Malaysia. Malay Nat. J. 43: 282-288.
LUNDBLAD O. 1933: Zur Kenntnis der aquatilen und semiaquatilen Hemipteren von Sumatra, Java und Bali. Arch. Hydrobiol. (Suppl.) 12: 1-195, 263-489, 21 Tafeln.

PAPÁČEK M. 1993: $K$ problematice morfologie a bionomie vodnich ploštic nadčeledi Pleoidea a Notonectoidea (Heteroptera: Nepomorpha). [On the Morphology and Bionomy of Water Bugs of the Superfamilies Pleoidea and Notonectoidea (Heteroptera: Nepomorpha)]. Thesis, University of South Bohemia, České Budějovice, 232 pp. (in Czech and English).

PAPÁČEK M. 1994: Idiotrephes maior sp. n., a new species of water bug from Vietnam with morphological notes on I. chinai (Heteroptera: Helotrephidae). Eur. J. Entomol. 91: 419-428.

PAPÁČEK M. 1995: Idiotrephes meszarosi sp. n., a new helotrephid (Heteroptera: Helotrephidae) from Vietnam. Aquat. Insects 17: 105-111.

PAPÁČEK M., ŚTYs P. \& Tonner M. 1988: A new subfamily of Helotrephidae (Heteroptera, Nepomorpha) from southeast Asia. Acta Entomol. Bohemoslov. 85: 120-154.

PAPÁČEK M., ŠTYS P. \& TONNER M. 1989: A new genus and species of Helotrephidae from Afghanistan and Iran (Heteroptera, Nepomorpha). Věst. Čs. Spol. Zool. 53: 107-122.

Polhemus J.T. 1990: A new tribe, a new genus and three new species of Helotrephidae (Heteroptera) from Southeast Asia, and a world checklist. Acta Entomol. Bohemoslov. 87: 45-63.

Zettel H. 1995: Neue Arten der Gattung Distotrephes Polhemus, 1990, aus China und Borneo sowie faunistische Notizen zu anderen Limnotrephini (Insecta: Heteroptera: Helotrephidae). Ann. Naturhist. Mus. Wien (B) 97: 159-168.

ZetTEL H. 1997a: One new genus and two new species of Helotrephidae (Insecta: Heteroptera) from India, with notes on the phylogeny of the family. Ann. Naturhist. Mus. Wien (B) 99: 83-95.

ZETTEL H. 1997b: Notes on Helotrephidae (Insecta: Heteroptera) from Borneo, with descriptions of two new species of the genera Fischerotrephes Zettel, 1994, and Trephotomas Papáček, Štys \& Tonner, 1988. Entomol. Problems 28: 117-126.

Zettel H. 1998: Introduction to the Helotrephidae (Nepomorpha) in Thailand and adjacent countries. Amemboa 2: $15-18$.

Zettel H. 1999: Notes on the genus Distotrephes (Heteroptera: Helotrephidae): new species from Thailand, Laos, and China, a key to species and first description of the alate morph. Acta Soc. Zool. Bohem. 63 : 251-266.

Note added after acceptance. Our colleagaue, Dr. John T. Polhemus, has a different opinion on the species concept of $I$. chinai and $I$. asiaticus than that presented here. Recently, he sent us cca 40 further specimens of $I$. cf. chinai and $I$. cf. asiaticus from his collection for examination. The problem is thus still open.

Received June 1, 1999; accepted April 13, 2000 